of these articles I have now in hand and expect to report on them at a later time.

Northwestern UNIVERSity Medical School, ChICAgo, ILL.

\title{
THE SEPARATION OF CLAY IN THE ESTIMATION OF HUMUS,
}

BY C. A. MOOERS AND H. H, HaMpton.

Received March 6, I908.

That a serious error may be introduced into the estimation of humus by the official method has been pointed out by a number of investigators. The chief cause of this error has been the weighing of clay with the humus extract and the consequent reckoning of the combined water in the clay as humus. To avoid this difficulty, Cameron and Breazeale ${ }^{1}$ filtered the extract through a Pasteur-Chamberland filter and determined the humus in the clear filtrate; Peter and Averitt ${ }^{2}$ have suggested the use of a factor with which to make a correction for the loss in the clayey residue; and a third, or evaporation method has been used by the authors. ${ }^{3}$ This paper presents a comparison of the results obtained by the three methods.

In the filtration method the ammoniacal humus extract is filtered through a Pasteur-Chamberland filter, which retains all the clay, and the humus is estimated as usual, by evaporation, etc., of the clear filtrate. In getting the results here reported, a silver-plated, containing tube was used on account of the ready solubility in ammonia of the copper of the usual brass tube.

By the factor method Peter and Averitt make a deduction from the total loss in weight of Io per cent. of the residue left after the humus has been burnt off. In Table I are given the results obtained by making both a Io per cent. and a 14 per cent. deduction.

In the evaporation method the ammoniacal humus extract containing clay in suspension is evaporated to dryness over a steam bath, by which means the clay is flocculated so that after extraction with 4 per cent. ammonia it can be retained on a common filter paper. Two evaporations and filtrations are necessary as a rule in order to get a clear filtrate, in which the humus is determined as usual.

The percentages in the first column, obtained with clay present, are not only liable to be irregular, as is shown under 636 , but are undoubtedly too high even when the clay is allowed to settle out for several weeks before taking out the aliquot portion for evaporation, as was done for Nos. 602 and 666.

2 ThIS JOURNAL, 26, 29-45.

${ }^{2}$ Ky. Sta. Bull., No. 126, pp. 63-126.

'Tenn. Sta. Bull., Vol. I9, No. 4, p. 50. 
Table I.-Per Cext. of Humus Estimated by the Different Methods in ReprliSENTATIVE I'ENNESSEE SOILS.

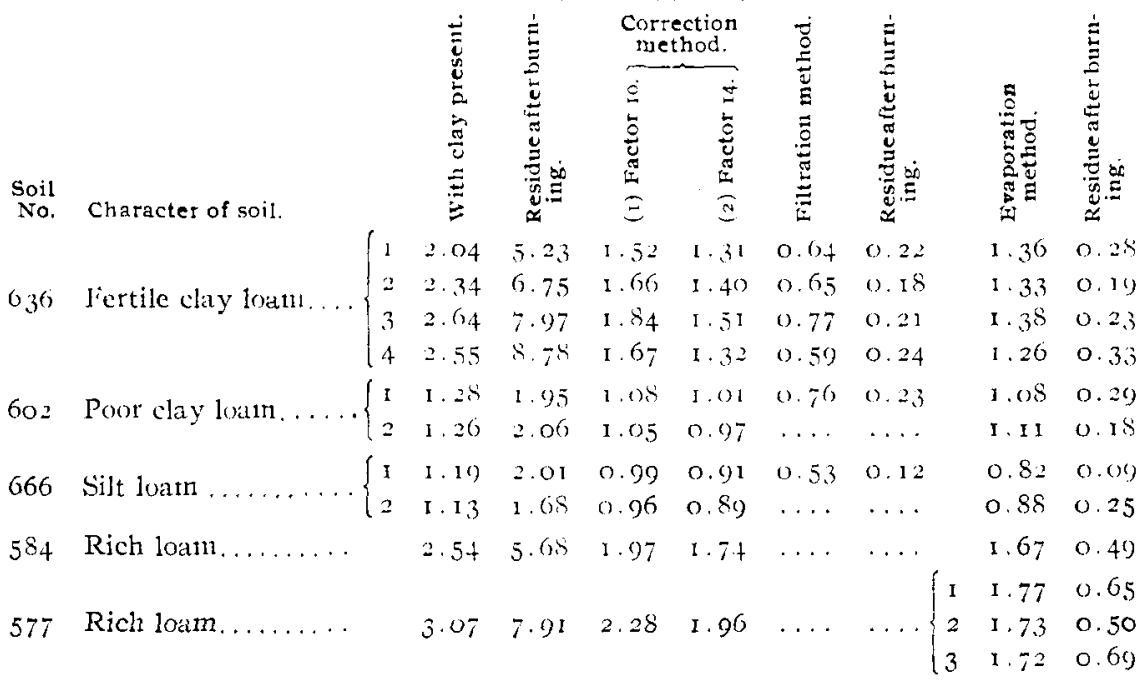

'The correction method undoubtedly gives better results than the preceding, but the duplications of Nos. 636 are not concordant, and there is a question as to the proper factor. For these soils a 14 per cent. rather than a Io per cent. correction gives the most harmonious results.

The filtration method proved highly unsatisfactory, chiefly on account of the humus absorbed by the filter. No simple way to avoid this defect was found. The first three results on No. 636 were obtained from successive filtrations of the same solution. These filtrations were made after the first runnings had been discarded. Each of the after parts that were analyzed represented about one-third of the remaining liquid. The fact that by the evaporation method, in which perfectly clear solutions were obtained, the results were, in round numbers, from 40 to row per cent. greater than those gotten by the use of the filter, is conclusive evidence of the inadequacy of the filtration method.

The evaporation method yielded at least fairly concordant results, but as they were obtained in the early part of our work they are probably not as uniform as the method will permit under close attention to details.

In Table II are given the percentages of humus by the evaporation method, and of total nitrogen by the Kjeldahl method, found in adjacent plots of an experimental field at the Tennessee Experiment Station farm. Lime had been applied to one-half of each of the plots at the rate of $\mathrm{r} 800$ pounds per acre three years before the samples were taken for analysis. The results indicate that by the aid of this simple modification small changes in the humus-content of a soil can be measured. 
TAble II.-EFfect of Liming on the Humus and Nitrogen Contents of Solls From Adjacent Plots.

\begin{tabular}{|c|c|c|c|c|c|}
\hline \multirow[b]{2}{*}{$\begin{array}{l}\text { Plot } \\
\text { No. }\end{array}$} & \multirow[b]{2}{*}{ Fertilized with } & \multicolumn{2}{|c|}{ Iimed half. } & \multicolumn{2}{|c|}{ Unlimed half. } \\
\hline & & 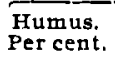 & $\begin{array}{l}\text { Nitrogen. } \\
\text { Per cent. }\end{array}$ & $\begin{array}{l}\text { Humus. } \\
\text { Per cent. }\end{array}$ & $\begin{array}{l}\text { Nitrogen. } \\
\text { Per cent. }\end{array}$ \\
\hline $\mathrm{F}_{4}$ & Mineral Fertilizer............ & $\ldots 1.28$ & o. II9 & $1 \cdot 32$ & o. II \\
\hline $\mathrm{F}_{5}$ & "r $\quad$ " $\ldots \ldots \ldots \ldots \ldots$ & . 1.38 & $0.12 I$ & I. 42 & 0.129 \\
\hline F6 & Farmyard manure............. & .1 .47 & 0.131 & I. 47 & o. 136 \\
\hline F8 & Mineral fertilizer........... & I. 37 & 0.126 & I. $4 \mathrm{I}$ & 0.126 \\
\hline $\mathrm{G}_{4}$ & $" \quad " \quad \ldots \ldots \ldots \ldots \ldots \ldots$ & 1.32 & 0.122 & I $\cdot 37$ & o. II \\
\hline $\mathrm{G}_{5}$ & $" \quad " \quad \ldots \ldots \ldots \ldots \ldots \ldots$ & . 1.33 & 0.118 & I. 34 & 0.125 \\
\hline G6 & $\begin{array}{l}\text { Farmyard manure and mineral fer- } \\
\text { tilizer. } \ldots \ldots \ldots \ldots \ldots \ldots \ldots \ldots\end{array}$ & 1.39 & 0.126 & I. 42 & 0.131 \\
\hline G8 & Mineral fertilizer............ & . 1.04 & 0.100 & I. IO & o. 108 \\
\hline & 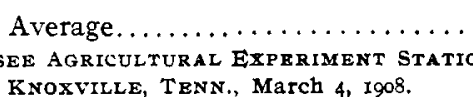 & $\begin{array}{l}\mathrm{r} \cdot 32 \\
\text { ION, }\end{array}$ & 0.120 & $I .36$ & 0.124 \\
\hline
\end{tabular}

(CONTRIBUtIONS FROM THE HAVEMEYer LABORATORIES OF COLUMbia UNIVERSity, No. I5I.)

\section{RESEARCHES ON QUINAZOLONES (TWENTIETH PAPER) ON CER- TAIN 7-NITRO-2-METHYL-4-QUINAZOLONES FROM 4-NITROACETANTHRANIL. ${ }^{1}$}

By Marston Taylor Bogert and William KLaber.

Received Febuaty 28, 1908 .

Bogert and Steiner ${ }^{2}$ and Bogert and Seil ${ }^{3}$ have already reported on the synthesis of 7-nitro-2-methyl-4-quinazolones from 4-nitroacetanthranil and various primary amines by the Anschütz, Schmidt and Greiffenberg ${ }^{4}$ reaction. The present paper records the continuation and extension of this work.

The reacion involved is a simple one, and may be conveniently expressed as follows:

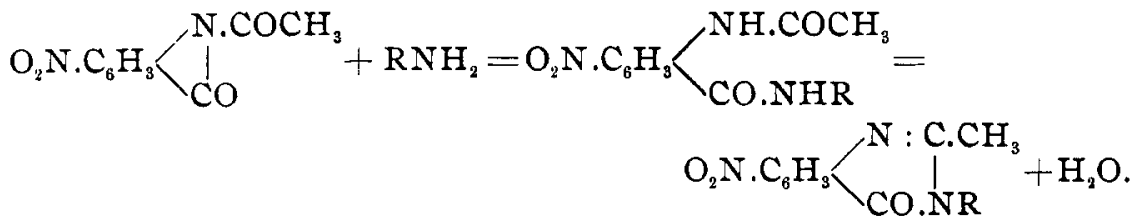

In one or two cases we isolated the intermediate amide.

The primary monamines used were ammonia, methyl-, $n$-propyl-, benzyl- and $\beta$-naphthylamines, aniline and $p$-anisidine. All of these

${ }^{1}$ Read at the General Meeting of the American Chemical Society, December 28, 1906 .

2 This Journal, 27, 1327 (1905).

3 Ibid., 29, 517 (1907).

4 Ber., 35, 3480 (1902). 